\title{
Prognostic and diagnostic significance of IncRNAs expression in cervical cancer: a systematic review and meta-analysis
}

\author{
Shuqi Chi ${ }^{1, *}$, Lina Shen ${ }^{1, *}$, Teng Hua ${ }^{1, *}$, Shuangge Liu ${ }^{1}$, Guobing Zhuang ${ }^{1}$, Xiaoxiao \\ Wang ${ }^{1}$, Xing Zhou ${ }^{1}$, Guozhen Wang ${ }^{1}$ and Hongbo Wang ${ }^{1}$ \\ ${ }^{1}$ Department of Obstetrics and Gynecology, Union Hospital, Tongji Medical College, Huazhong University of Science and \\ Technology, Wuhan 430022, China \\ * These authors have contributed equally to this work \\ Correspondence to: Hongbo Wang, email: hb_wang1969@sina.com \\ Keywords: cervical cancer, long noncoding RNA, prognosis, diagnosis, meta-analysis \\ $\begin{array}{lll}\text { Received: February 14, } 2017 \quad \text { Accepted: April 17, } 2017 & \text { Published: May 31, } 2017\end{array}$
}

Copyright: Chi et al. This is an open-access article distributed under the terms of the Creative Commons Attribution License 3.0 (CC BY 3.0), which permits unrestricted use, distribution, and reproduction in any medium, provided the original author and source are credited.

\section{ABSTRACT}

Long noncoding RNAs (IncRNAs) have been reported to be abnormally expressed in cervical cancer (CC) and presumably serve as diagnostic or prognostic markers. We thus performed a systematic review and meta-analysis to evaluate the clinical values of dysregulated IncRNAs in CC. A literature search was performed using the electronic databases PubMed, Embase, and Web of Science. A total of 22 relevant studies were eligible, including 21 on clinicopathological features, 18 on prognosis, and 4 on diagnosis. For clinicopathological features, HOTAIR expression was positively associated with tumor size (odds ratio [OR] $=2.19,95 \%$ confidence interval [CI] 1.423.38, $P=0.000$ ) and lymph node metastasis ( $O R=6.04,95 \% \mathrm{CI} 3.51-10.42, P=0.000)$. For the prognostic values, up-regulated HOTAIR had an unfavorable impact on overall survival ([OS]; hazard ratio $[H R]=1.94,95 \% C I 1.17-3.22, P=0.011$ ) and diseasefree survival ( $\mathrm{HR}=2.61,95 \% \mathrm{CI} 1.35-5.05, P=0.004)$, and high PVT1 expression was correlated with shorter OS $(\mathrm{HR}=1.66,95 \% \mathrm{CI} 1.21-2.29, P=0.002)$. For the diagnostic values, the pooled result showed an area under the curve (AUC) of 0.85 , with $85 \%$ sensitivity and $81 \%$ specificity in discriminating patients with CC from healthy controls. Overall, we conclude that IncRNAs might serve as promising indicators for prognostic and diagnostic evaluation of patients with $\mathrm{CC}$.

\section{INTRODUCTION}

Cervical cancer (CC) is the fourth most commonly diagnosed cancer and the fourth leading cause of cancerrelated death among females worldwide, with 527,600 new female cancer cases and 265,700 deaths worldwide in 2012 [1]. With the improvement of diagnostic techniques and therapeutic strategies, the incidence and mortality rates of CC has decreased [2]. However, the overall prognosis of CC patients still remains poor, especially in developing countries [3]. Currently, there are few factors that can be applied to effectively predict the incidence and mortality rates of cancer patients because of the numerous and complex risk factors for CC. Squamous cell carcinoma antigen (SCC-Ag) [4] is a commonly used marker for diagnosis, but low sensitivity and specificity limit its utility. Under such circumstances, it can be clinically challenging to determine novel biomarkers for prognosis and diagnosis of $\mathrm{CC}$.

During the past decades, there has been an explosive growth in knowledge regarding lncRNAs in the field of RNA biology. LncRNAs are broadly defined as RNA molecules greater than $200 \mathrm{nt}$ in length, lacking an open reading frame [5], and they are regulators of gene expression at the chromatin-organizational, transcriptional and post-transcriptional levels [6]. Accumulating evidence has demonstrated that lncRNAs play a non-negligible role during the process of proliferation, migration, and invasion of tumor cells [7-10]. Recently, a relationship between the expression of particular lncRNAs and the survival of cancer patients has also been increasingly reported, especially HOTAIR, a highly oncogenic lncRNA in numerous human malignancies. Furthermore, a large number of observational studies have been 
carried out to investigate the prognostic and diagnostic role of certain lncRNA in CC lately. To date, a large number of observational studies have been performed to investigate the prognostic and diagnostic role of certain lncRNAs in CC. For example, Yang et al. [11] found that serum expression of the lncRNA PVT1 is higher in CC patients, with $71.6 \%$ sensitivity and $98.8 \%$ specificity. Another study reported that the lncRNA XLOC_010588 was significantly down-regulated in $\mathrm{CC}$ patients and was associated with poor prognosis [12]. With the aim of synthesizing the results of these studies to gain better insight into the clinical value of lncRNAs, we performed a systematic review and meta-analysis to quantify the predictive efficacy of lncRNAs in the aspects of clinicopathological features, prognosis and diagnosis in $\mathrm{CC}$ patients.

\section{RESULTS}

\section{Study selection and characteristics}

As shown in the flow diagram (Figure 1), 225 records were initially identified from PubMed, Embase and Web of science. After screening the titles and abstracts of these studies, 185 duplicate or irrelevant articles were excluded. Subsequently, the remaining 40 fulltext articles were assessed for eligibility, and 17 studies, including 14 without sufficient clinical data, 1 with less than 30 samples, and 2 with discussions on lncRNA polymorphism, were further excluded on the basis of the exclusion criteria. No additional studies were identified through our manual search of references from published studies, relevant reviews, and previous meta-analyses. As a result, 22 eligible studies [11-32] encompassing 2363 patients were included in this systematic review and metaanalysis.

All the selected studies were published between 2014 and 2017, including 21 on clinicopathological features, 18 on prognosis and 4 on diagnosis. Most of the studies were from China $(77.3 \%)$, followed by Korea (13.7\%), Japan (4.5\%) and America (4.5\%). Quantitative real-time polymerase chain reaction (qRT-PCR) assays were used to quantify the lncRNAs in all of the studies. Specimens were composed of tissue $(n=20)$ and serum $(n=2)$. Of the total 15 lncRNAs, 4 (HOTAIR, MALAT1, PVT1 and MEG3) were investigated by at least two studies, and the remaining 11 lncRNAs were studied in a single report. Additionally, $94.44 \%$ of the NOS scores for the included studies on prognosis were $\geq 7$ (Supplementary Table 1), and all of the Quality Assessment of Diagnostic

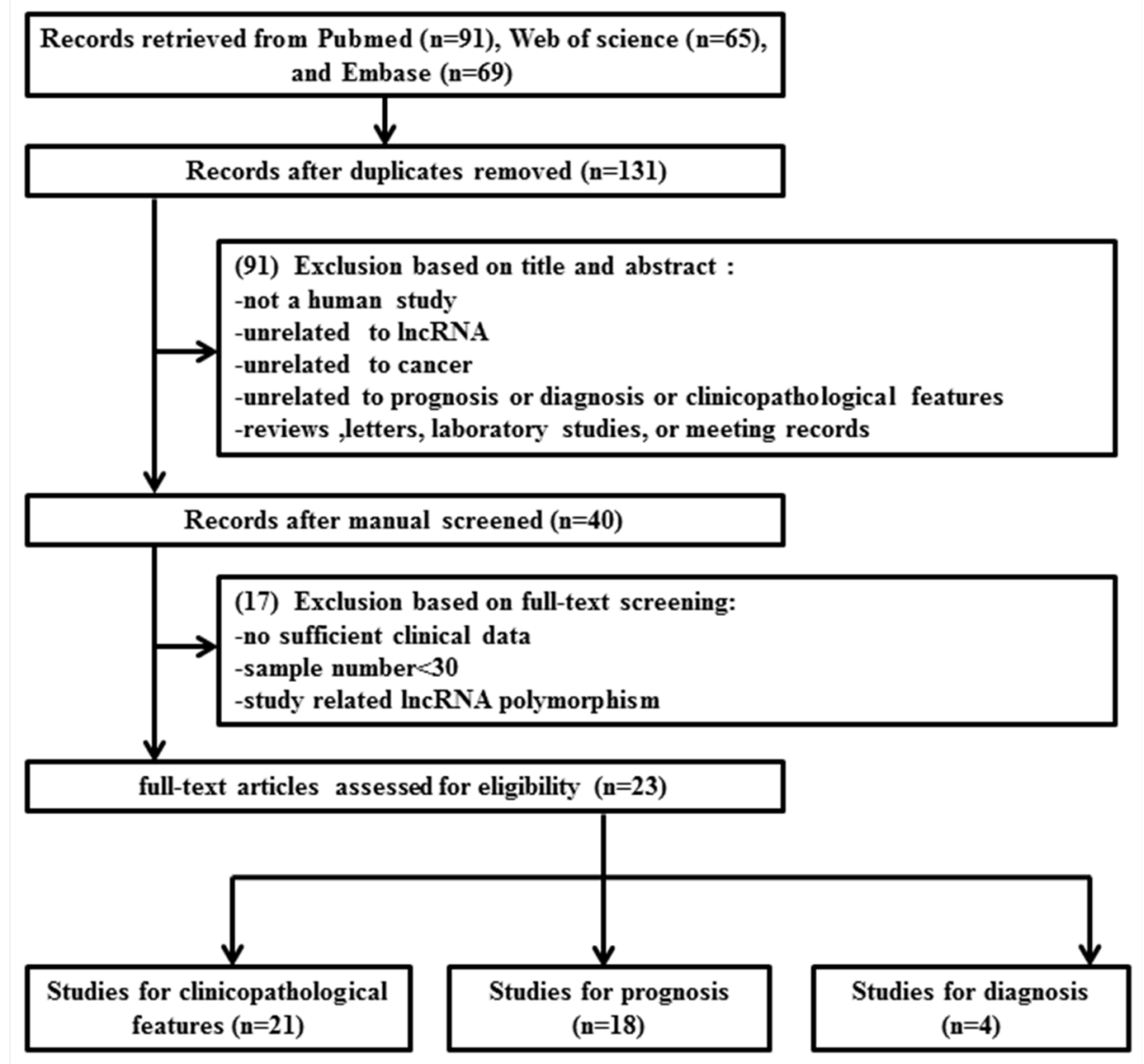

Figure 1: Flow chart of the literature search and selection. 
Table 1:Summary of the comparison for the p values of the association between IncRNAs and clinicopathological features

\begin{tabular}{|c|c|c|c|c|c|c|c|c|c|c|c|c|c|}
\hline studies & LncRNAs & Population & \begin{tabular}{|l|} 
Case \\
number
\end{tabular} & Cut-off & Expression & Age & $\begin{array}{l}\text { Tumor } \\
\text { size }\end{array}$ & Histology & $\begin{array}{l}\text { FIGO } \\
\text { stage }\end{array}$ & Differentiation & \begin{tabular}{|l} 
Lymph \\
node \\
metastasis
\end{tabular} & $\begin{array}{l}\text { Scc-Ag } \\
(\mu \mathrm{g} / \mathrm{l})\end{array}$ & $\begin{array}{l}\text { Lymphovascular } \\
\text { space invasion }\end{array}$ \\
\hline Cao 2014 & GAS5 & Chinese & 102 & median & $\begin{array}{l}\text { down- } \\
\text { regulation }\end{array}$ & 0.187 & 0.386 & 0.851 & NA & 0.462 & NA & NA & NA \\
\hline Huang 2014 & HOTAIR & Chinese & 218 & median & up-regulation & 0.02 & 0.006 & 0.686 & $<0.0001$ & 0.519 & $<0.0001$ & 0.724 & $\mathrm{NA}$ \\
\hline Liao 2014 & XLOC_010588 & Chinese & 218 & median & $\begin{array}{l}\text { down- } \\
\text { regulation }\end{array}$ & 0.336 & $<0.0001$ & 0.686 & $<0.0001$ & 0.273 & 0.07 & 0.006 & NA \\
\hline Chen 2015 & CCAT2 & Chinese & 123 & median & up-regulation & 0.415 & 0.514 & NA & 0.003 & NA & NA & NA & NA \\
\hline Jiang 2015 & LET & Chinese & 94 & mean & $\begin{array}{c}\text { down- } \\
\text { regulation }\end{array}$ & 0.867 & 0.929 & 0.732 & NA & 0.057 & 0.004 & NA & NA \\
\hline Kim 2015 & HOTAIR & Korean & 111 & $\begin{array}{l}\text { fold- } \\
\text { change }\end{array}$ & up-regulation & 0.8809 & 0.8839 & 0.2334 & 0.7671 & $\mathrm{NA}$ & 0.0437 & NA & 0.6351 \\
\hline Yang 2015 & CCHE1 & Chinese & 182 & median & up-regulation & 0.374 & $<0.001$ & 0.466 & 0.002 & 0.432 & 0.283 & 0.004 & NA \\
\hline Yang 2015 & MALAT1 & Chinese & 104 & median & up-regulation & 0.43 & 0.005 & 0.6 & 0.01 & 0.49 & 0.0002 & NA & $\mathrm{NA}$ \\
\hline Zhang 2015 & HOTAIR & Chinese & 36 & median & up-regulation & 0.821 & 0.013 & 0.451 & 0.002 & 0.527 & 0.02 & 0.829 & NA \\
\hline Zhang 2015 & MALAT1 & Chinese & 30 & NA & up-regulation & 0.653 & 0.04 & NA & 0.03 & $\mathrm{NA}$ & NA & NA & NA \\
\hline Zhang 2015 & MEG3 & Chinese & 108 & $\mathrm{NA}$ & $\begin{array}{l}\text { down- } \\
\text { regulation }\end{array}$ & 0.15 & $<0.01$ & 0.16 & $<0.01$ & 0.12 & $<0.01$ & NA & 0.22 \\
\hline Саo 2016 & SPRY4-IT1 & Chinese & 100 & \begin{tabular}{|l}
$\begin{array}{l}\text { fold- } \\
\text { change }\end{array}$ \\
\end{tabular} & up-regulation & 0.068 & $<0.001$ & 0.954 & $<0.001$ & 0.046 & $<0.001$ & NA & NA \\
\hline Kim 2016 & HOXA11-AS & Korean & 91 & \begin{tabular}{|l|} 
fold- \\
change
\end{tabular} & up-regulation & 0.734 & NA & 0.098 & 0.23 & NA & 0.142 & $\mathrm{NA}$ & 0.052 \\
\hline $\begin{array}{l}\text { KOBAYASHI } \\
2016\end{array}$ & XIST & Japanese & 49 & median & $\begin{array}{l}\text { down- } \\
\text { regulation }\end{array}$ & 0.12 & 0.87 & NA & 0.81 & NA & 0.11 & NA & NA \\
\hline Lee 2016 & HOTAIR & Korean & 153 & $\begin{array}{l}\text { fold- } \\
\text { change }\end{array}$ & up-regulation & 0.835 & 0.03 & 0.711 & 0.413 & NA & 0.043 & 0.732 & 0.037 \\
\hline Sun 2016 & HOTAIR & Chinese & 59 & NA & up-regulation & 0.6321 & 0.5132 & 0.0063 & 0.0154 & NA & 0.0214 & NA & 0.038 \\
\hline Wang 2016 & HULC & Chinese & 244 & median & up-regulation & 0.883 & 0.256 & 0.72 & 0.001 & NA & $\mathrm{NA}$ & NA & NA \\
\hline Yang 2016 & PVT1 & Chinese & 88 & NA & up-regulation & NA & $<0.001$ & $\mathrm{NA}$ & $<0.001$ & NA & $<0.001$ & NA & NA \\
\hline Zhang 2016 & ANRIL & Chinese & 51 & median & up-regulation & 0.449 & 0.219 & 0.696 & 0.009 & 0.168 & 0.031 & NA & NA \\
\hline Zhang 2016 & PVT1 & Chinese & 90 & median & up-regulation & NA & $<0.01$ & NA & $<0.01$ & $\mathrm{NA}$ & $\mathrm{NA}$ & $\mathrm{NA}$ & NA \\
\hline Нu 2017 & TUG1 & Chinese & 40 & median & up-regulation & 0.533 & $<0.001$ & 1 & 0.009 & 0.007 & 0.015 & 0.083 & $\mathrm{NA}$ \\
\hline
\end{tabular}

Abbreviations: LncRNA, long non-coding RNA; FIGO, International Federation of Gynecology and Obstetrics; NA, not available

Accuracy Studies-2 (QUADAS-2) scores for studies on diagnosis were $\geq 4$, indicating a high quality for most of the studies (Supplementary Table 2).

\section{Clinicopathological features}

Twelve IncRNAs from 21 studies were available to evaluate the effect of their expression on clinicopathological features. The expression of HOTAIR [13-17], CCAT2 [18], CCHE1 [19], MALAT1 [20, 21], SPRY4-IT1 [22], HOXA11-AS [23], HULC [24], PVT1 $[11,25]$, ANRIL [26] and TUG1 [27] were up-regulated, while the expression of GAS5 [28], XLOC_010588 [12], LET [29], MEG3 [30] and XIST [31] were down-regulated in CC patients. Only a small number of studies reported that dysregulated lncRNAs were related to the level of SCC-Ag and lymphovascular space invasion; most of the studies reported that lncRNAs were significantly associated with tumor size, International Federation of Gynecology and Obstetrics (FIGO) stage and lymph node metastasis (Table 1).

It is worth mentioning that there were three lncRNAs (HOTAIR, MALAT1 and PVT1) investigated by at least 2 studies. MALAT1 and PVT1 were excluded because the information was incomplete. We then performed a meta-analysis to determine the possible relationship between HOTAIR overexpression and clinicopathological features. The data extracted from 5 studies $(n=577)[13-$ 17] were divided into 4 groups according to different clinicopathological features. No significant heterogeneity was found (tumor size, $I^{2}=0.0 \%, P=0.466$; histology, $I^{2}=$ $0.0 \%, P=0.667$; FIGO stage, $I^{2}=0.0 \%, P=0.858$; lymph node metastasis, $I^{2}=12.0 \%, P=0.337$ ) (Figure 2 ), and the fixed effect model was therefore utilized. The results revealed that high expression of HOTAIR was related to larger tumor size $(>4 \mathrm{~cm} v s \leq 4 \mathrm{~cm}$ : OR $=2.19,95 \% \mathrm{CI}$ $1.42-3.38, P=0.000)$. In addition, patients with lymph node metastasis exhibited higher expression of HOTAIR than those without metastasis, with a pooled OR of 6.04 (95\% CI 3.51-10.42, $P=0.000$ ). Furthermore, there was no clear connection between up-regulation of HOTAIR and $\mathrm{CC}$ histology (adenocarcinoma [AD]/adenosquamous cell carcinom [ASC] $v s$ squamous cell carcinoma [SCC]: OR $=0.92,95 \% \mathrm{CI} 0.58-1.46, P=0.714)$ or FIGO stage (III/IV vs I/II: OR $=0.89,95 \%$ CI $0.33-2.38, P=0.813)$.

\section{Prognosis}

Eighteen studies containing 2291 patients were available to investigate the relationship between lncRNA 
Table 2: Summary of IncRNAs used as prognostic biomarkers of CC

\begin{tabular}{|c|c|c|c|c|c|c|c|c|c|c|c|}
\hline \multirow[t]{2}{*}{ Studies } & \multirow[t]{2}{*}{ LncRNAs } & \multirow[t]{2}{*}{ Population } & \multirow{2}{*}{$\begin{array}{c}\text { Tumor } \\
\text { stage }\end{array}$} & \multicolumn{2}{|c|}{ Case number } & \multirow{2}{*}{$\begin{array}{c}\text { Detected } \\
\text { sample }\end{array}$} & \multirow{2}{*}{$\begin{array}{l}\text { Detection } \\
\text { methord }\end{array}$} & \multirow[t]{2}{*}{ Cut-off } & \multirow[t]{2}{*}{ Outcomes } & \multirow{2}{*}{$\begin{array}{c}\text { HR } \\
\text { availability }\end{array}$} & \multirow{2}{*}{$\begin{array}{c}\text { Follow-up } \\
\text { month }\end{array}$} \\
\hline & & & & High level & Low level & & & & & & \\
\hline Cao 2014 & GAS5 & Chinese & I b-IIIa & 58 & 44 & FT & qRT-PCR & median & os & directly & $44(0-60)$ \\
\hline Huang 2014 & HOTAIR & Chinese & I b- II b & 109 & 109 & FT & qRT-PCR & median & OS,DFS & directly & $42(2-55)$ \\
\hline Liao 2014 & XLOC_010588 & Chinese & I b- II b & 109 & 109 & $\mathrm{FT}$ & qRT-PCR & median & OS,DFS & directly & $42(2-55)$ \\
\hline Chen 2015 & CCAT2 & Chinese & I b-IIIIa & 62 & 61 & FT & qRT-PCR & median & OS,PFS & directly & $48(6-60)$ \\
\hline Jiang 2015 & LET & Chinese & I b-IIIla & 44 & 50 & FT & qRT-PCR & mean & OS & directly & 46 \\
\hline Kim 2015 & HOTAIR & Korean & $\mathrm{I} a-I V b$ & 89 & 22 & FT & qRT-PCR & fold-change & OS & indirectly & $\sim 64$ \\
\hline Yang 2015 & CCHE1 & Chinese & I b- II b & 91 & 91 & FT & qRT-PCR & median & OS,RFS & indirectly & $\sim 40$ \\
\hline Yang 2015 & MALAT1 & Chinese & I b-IIIa & 52 & 52 & FT & qRT-PCR & median & OS,RFS & directly & $30(8-60)$ \\
\hline Cao 2016 & SPRY4-IT1 & Chinese & I b- II b & 46 & 54 & FT & qRT-PCR & fold-change & OS & directly & $53(3-60)$ \\
\hline Iden 2016 & PVT1 & American & NA & 63 & 58 & FT & qRT-PCR & median & os & indirectly & $2-120$ \\
\hline Lee 2016 & HOTAIR & Korean & I -III & 92 & 61 & FS & qRT-PCR & fold-change & OS,DFS & directly & $55(1-99)$ \\
\hline Kim 2016 & HOXA11-AS & Korean & I -III & 92 & 30 & FT & qRT-PCR & fold-change & os & directly & 46.5 \\
\hline $\begin{array}{l}\text { KOBAYASHI } \\
2016\end{array}$ & XIST & Japanese & I -IV & 24 & 25 & FT & qRT-PCR & median & OS & indirectly & $44.1(5.2-142.1)$ \\
\hline Wang 2016 & HULC & Chinese & I b-IIIla & 120 & 124 & FT & qRT-PCR & median & OS & directly & $0-60$ \\
\hline Zhang 2016 & ANRIL & Chinese & I b-IIIa & 27 & 26 & FT & qRT-PCR & median & OS & directly & $0-60$ \\
\hline Zhang 2016 & PVT1 & Chinese & I - II & 45 & 45 & FT & qRT-PCR & median & OS & indirectly & $0-58$ \\
\hline Zhang 2017 & MEG3 & Chinese & I - II & 36 & 36 & $\mathrm{FT}$ & qRT-PCR & median & OS,RFS & directly & $0-36$ \\
\hline
\end{tabular}

Abbreviations: LncRNA, long non-coding RNA; FT, frozen tissue; qRT-PCR, quantities reverse transcription polymerase chain reaction; OS, overall survival; DFS, disease free survival; HR, hazard ratio

Study

ID

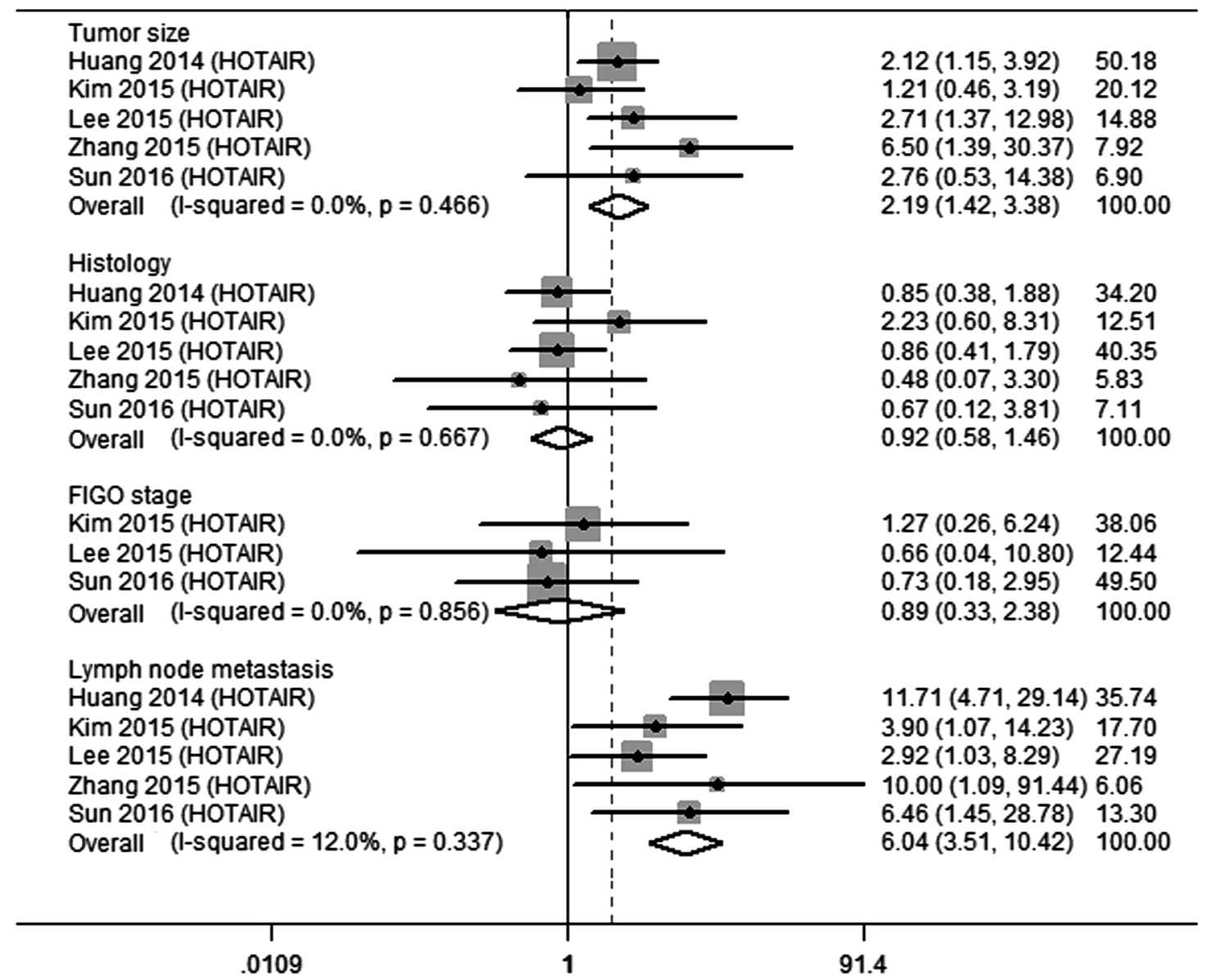

Figure 2: Qualitative meta-analysis of studies estimating ORs of up-regulated HOTAIR expression and the clinicopathology of CC patients. Abbreviations: OR, odds ratio; CI, confidence interval. 
Table 3: Summary of IncRNAs used as diagnostic biomarkers of CC

\begin{tabular}{|c|c|c|c|c|c|c|c|c|c|c|}
\hline \multirow{2}{*}{ Studies } & \multirow{2}{*}{ LncRNAs } & \multirow{2}{*}{ Population } & \multirow{2}{*}{ Expression } & \multirow{2}{*}{$\begin{array}{l}\text { Detected } \\
\text { sample }\end{array}$} & \multirow{2}{*}{ SE(\%) } & \multirow{2}{*}{ SP(\%) } & \multirow{2}{*}{ AUC } & \multicolumn{2}{|c|}{ Sample size } & \multirow{2}{*}{$\begin{array}{l}\text { QUADAS-2 } \\
\text { scores }\end{array}$} \\
\hline & & & & & & & & cancer & control & \\
\hline Huang 2014 & \begin{tabular}{|l} 
HOTAIR \\
\end{tabular} & Chinese & up-regulation & $\mathrm{FT}$ & $60.60 \%$ & $87.20 \%$ & 0.803 & 218 & 218 & 5 \\
\hline Liao 2014 & XLOC_010588 & Chinese & down-regulation & FT & $84.40 \%$ & $86.70 \%$ & 0.918 & 100 & 100 & 5 \\
\hline Cao 2016 & SPRY4-IT1 & Chinese & up-regulation & FT & $78.30 \%$ & $63.60 \%$ & 0.741 & 218 & 218 & 5 \\
\hline Yang 2016 & PVT1 & Chinese & up-regulation & Serum & $71.60 \%$ & $98.80 \%$ & 0.932 & 88 & 86 & 5 \\
\hline
\end{tabular}

Abbreviations: LncRNA, long non-coding RNA; FT, frozen tissue; SE, sensitivity; SP, specificity; AUC, area under the curve; QUADAS, quality assessment of diagnostic accuracy studies

expression and OS. Three studies reported DFS and PFS/ RFS data. The characteristics of these eligible studies are presented in Table 2. Increased expression of HOTAIR [13-15, 17], CCAT2 [18], CCHE1 [19], MALAT1 [20], SPRY4-IT1 [22], HOXA11-AS [23], HULC [24], PVT1 $[11,25]$, and ANRIL [26] were associated with a poor prognosis, together with decreased expression of GAS5 [28], XLOC_010588 [12], LET [29] and MEG3 [32] (Figure 3).

Two lncRNAs (HOTAIR and PVT1) were investigated in at least 2 studies, and we performed metaanalyses of the survival data. For HOTAIR, four studies ( $n$ $=541$ ) described the relationship between expression and outcome in CC patients, including 4 on OS $(n=541)$ and 2 on DFS $(n=371)$. We then incorporated these studies with OS and DFS separately. Fixed effects models were applied because the heterogeneity was not significant (OS, $I^{2}=34.0 \%, P=0.208 ;$ DFS, $\left.I^{2}=0.0 \%, P=0.424\right)$. The results revealed that high expression of HOTAIR was a predictive factor of shorter OS (HR, $1.94,95 \% \mathrm{CI} 1.17$ $3.22, P=0.011$ ), as well as DFS (HR, 2.61, 95\%CI 1.35$5.05, P=0.004$ ) (Figure 4A). It is worth noting that before reintegration was performed, up-regulation of HOTAIR was independent of OS according to the clinical data given by the two studies $[14,17]$. However, the results of our pooled analysis indicated HOTAIR as a prognostic factor.

As for PVT1, two studies $(n=211)$ assessed that raised PVT1 levels yielded a worse OS in CC patients. Because of the low heterogeneity $\left(I^{2}=22.2 \%, P=\right.$ $0.510)$, the fixed effects model was used. The subsequent combined adjusted HR for PVT1 was 1.66 (95\%CI 1.212.29, $P=0.002$ ) (Figure 4B).

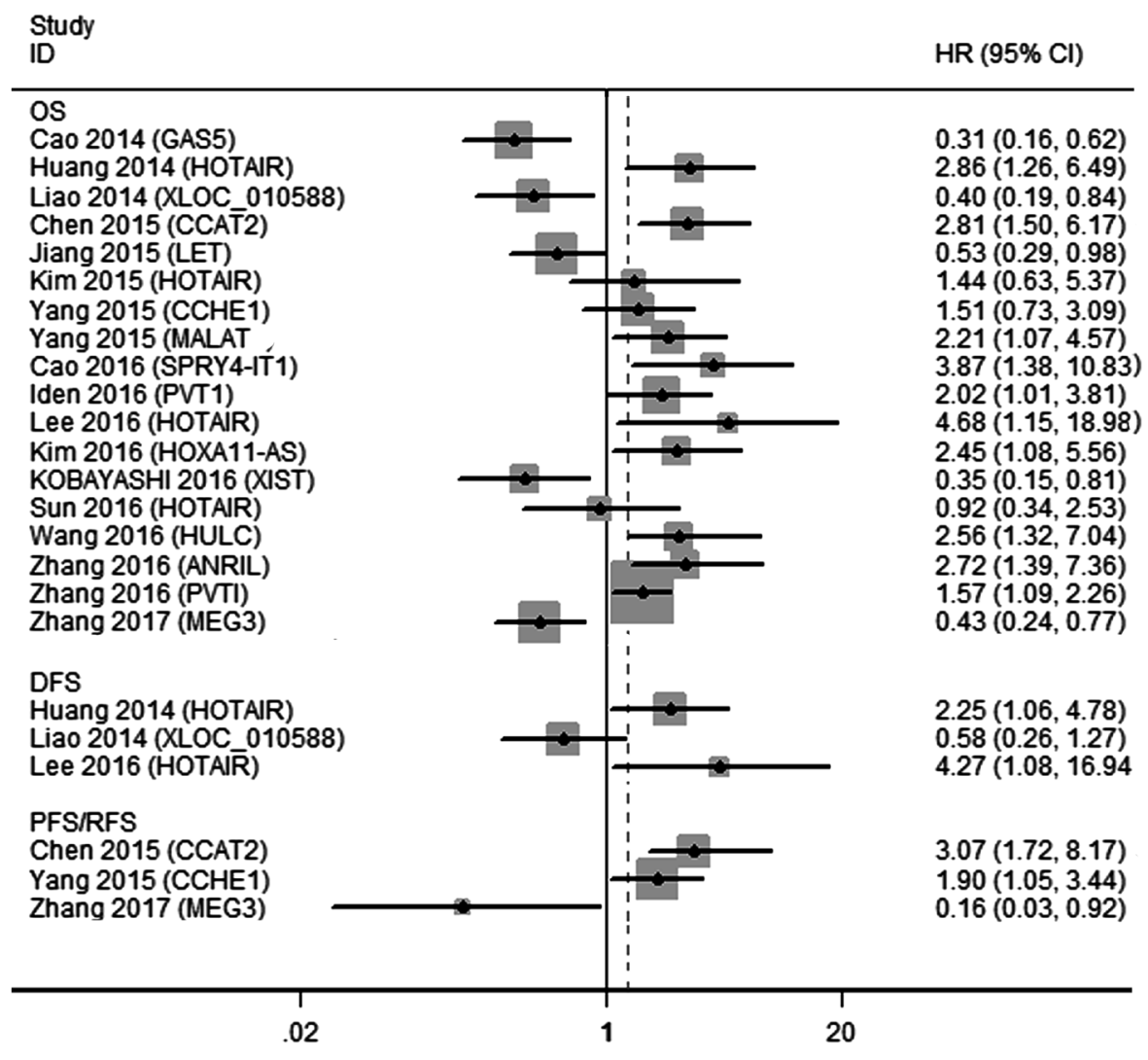

Figure 3: A display of HRs of IncRNAs in CC patients. Abbreviations: OS, overall survival; DFS, disease-free survival; PFS, progression-free survival; RFS, recurrence-free survival; HR, hazard ratio; CI, confidence interval. 


\section{Diagnosis}

Only 4 studies, discussing XLOC_010588 [12], HOTAIR [13], SPRY4-IT1 [22] and PVT1 [25], provided complete diagnosis-related data, among which, 3 were based on cervical tissues as specimens and 1 on serum (Table 3). Forest plots of the sensitivity and specificity of lncRNA for diagnosing CC are displayed in Figure 5. A significant heterogeneity was observed $\left(I^{2}=94.64 \%\right.$ and $I^{2}=90.68 \%$ ), and thus, a more conservative random effect model was used. The summary estimates are as follows: sensitivity (SEN), 0.85 (95\%CI 0.63-0.95); specificity (SPE), 0.81 (95\%CI 0.70-0.88); positive likelihood ratio (PLR), 4.37 (95\%CI 2.83-6.74); negative likelihood ratio (NLR), 0.19 (95\%CI 0.07-0.50); and overall diagnostic odds ratio (DOR), 23.18 (95\%CI, 7.19-74.70). In addition, we generated a summary receiver operator characteristic (SROC) curve (Figure 6) and calculated the area under the curve (AUC) $(0.88,95 \%$ CI $0.85-0.90)$. These results suggested that lncRNAs achieved a relatively high diagnostic accuracy. Although large heterogeneity in this analysis was noted, we did not conduct meta-regression or subgroup analysis due to the small numbers and small sample sizes of the included studies. Therefore, further studies should be performed to verify this conclusion.

\section{Publication bias}

In the present meta-analysis, we utilized Begg's and Egger's tests [33], as well as funnel plots, to evaluate the publication bias of the incorporated studies. As presented in Figure 7, our analyses suggested no evident asymmetry publication bias with regard to the studies on HOTAIR using Egger's test ( $P=0.406$ for tumor size, $P=0.927$ for lymph node metastasis, and $P=0.922$ for OS). For PVT1, no conclusive graph could be generated due to the small size of the associated studies, and we therefore did not evaluate publication bias. For diagnostic studies, a Deeks'

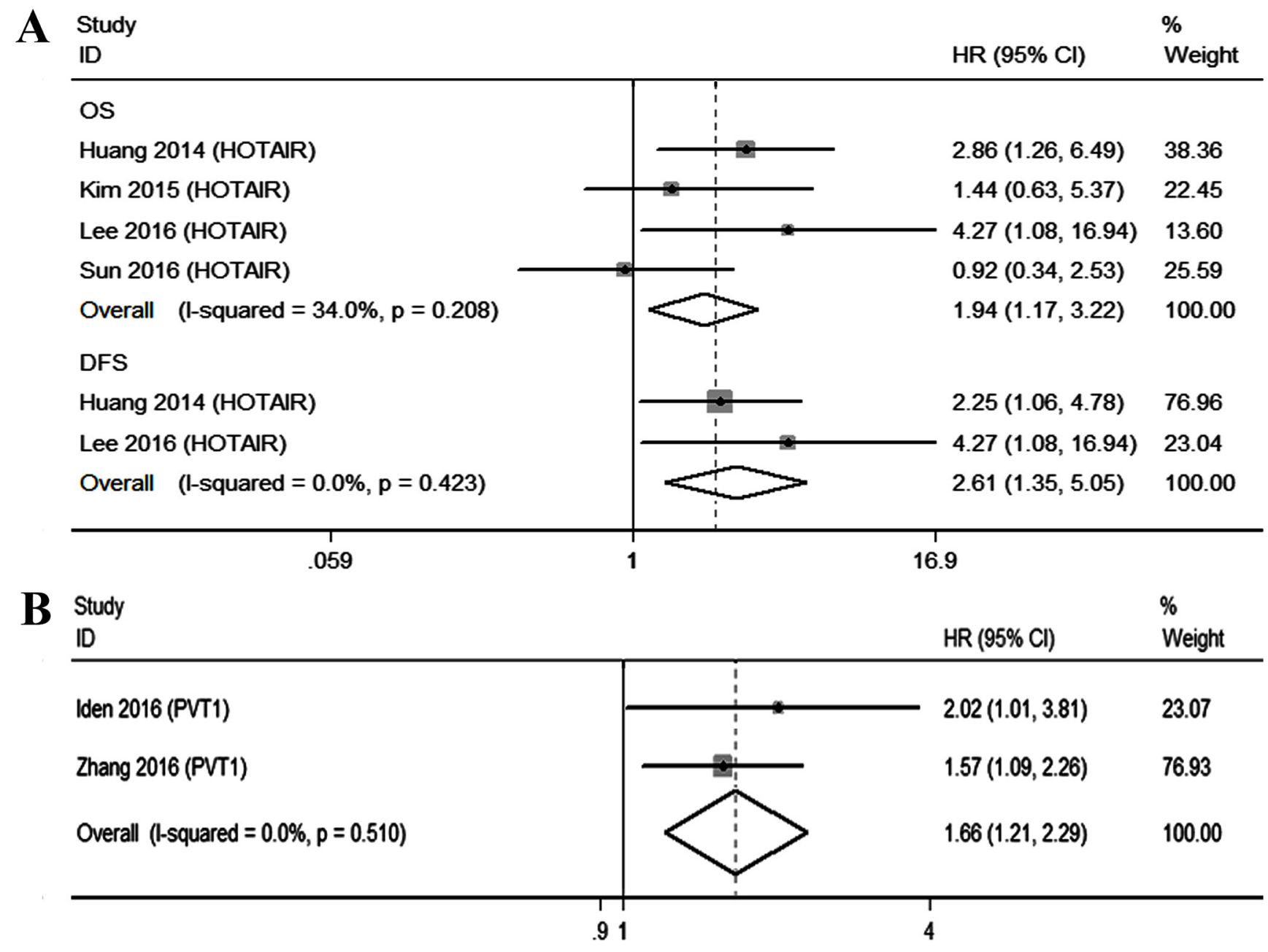

Figure 4: Qualitative meta-analysis of studies estimating the relationship between IncRNA expression and the prognosis of patients with CC. A. HOTAIR B. PVT1. Abbreviations: OS, overall survival; DFS, disease-free survival; HR, hazard ratio; CI, confidence interval. 
funnel plot asymmetry test [34] was conducted, and there was no clear evidence of publication bias $(P=0.51)$ in this meta-analysis.

\section{DISCUSSION}

Within a relatively short period of time, accumulating studies have indicated that lncRNAs are frequently abnormally expressed in CC. These lncRNAs are likely to serve as diagnostic and prognostic biomarkers and may be potential targets for individualized therapy, but the relatively small sample sizes and noisiness of microarray data have produced inconsistent biological conclusions. The systematic review and meta-analysis presented here is the first comprehensive description of independent profiling experiments investigating the effect of IncRNA expression on the clinical values of CC.

In this study, we examined the correlation between lncRNAs and the main clinicopathological characteristics of CC. The results revealed that patients with dysregulated lncRNA expression were more likely to have a high histological grade and FIGO stage, lymph node metastasis deep cervical invasion and large tumor size. Among the included publications, HOTAIR was the most widely investigated lncRNA, as it was reported in 5 studies. The pooled data illustrated that HOTAIR expression was remarkably correlated with tumor size and lymph node metastasis in CC patients. Unsurprisingly, a recent meta-analysis of lncRNA in all human cancers [35] has some overlap with our pooled analysis, specifically, increased HOTAIR expression is often found in cancer patients with lymph node metastasis compared to those without metastasis $(\mathrm{OR}=2.81,95 \%$ CI $1.38-5.70, P=$
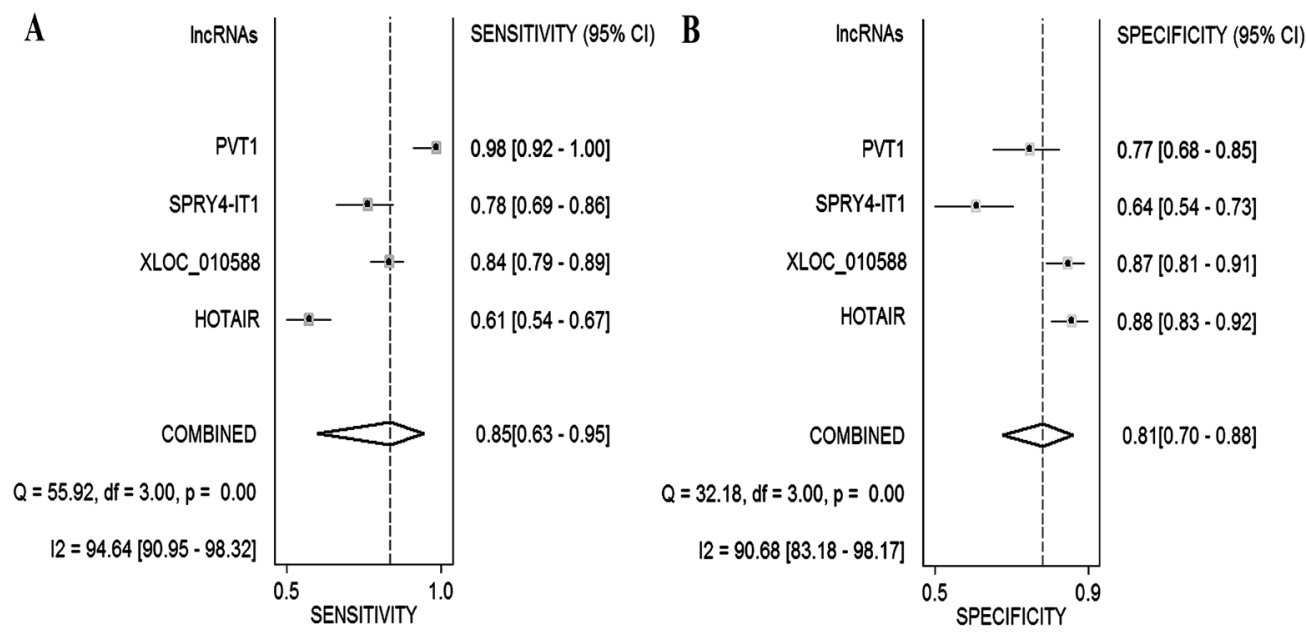

Figure 5: Forest plot of sensitivity and specificity of IncRNAs for the diagnosis of CC. A. sensitivity B. specificity.

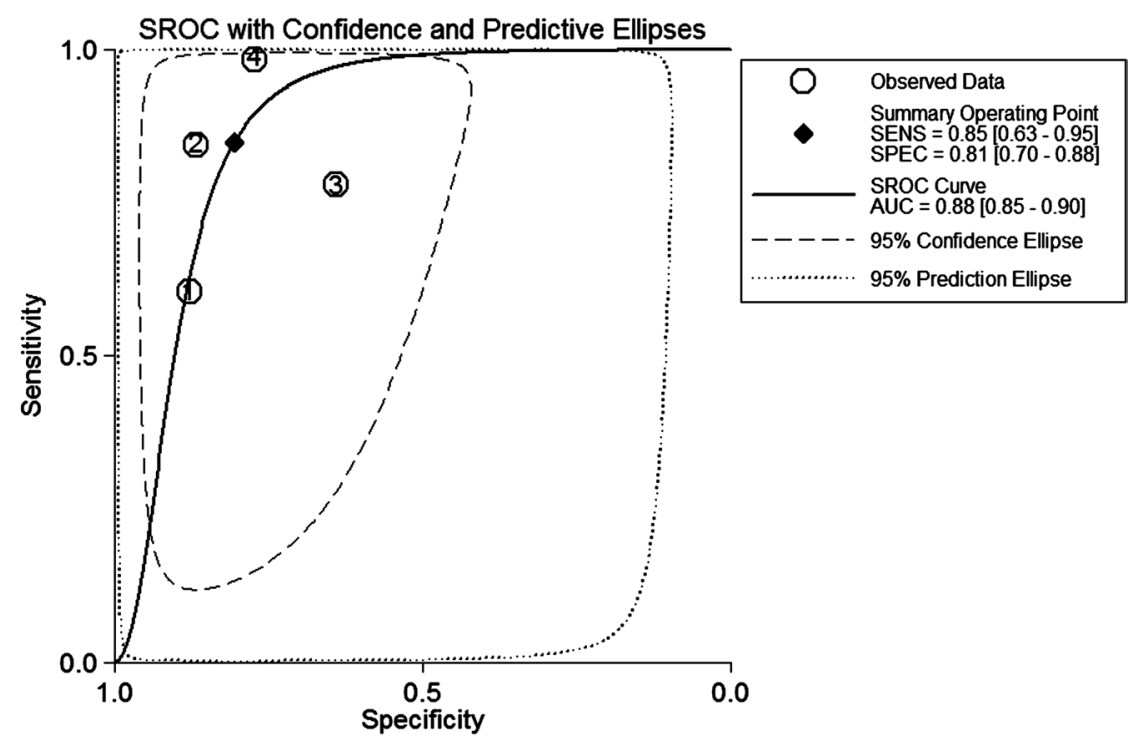

Figure 6: The summary receiver operator characteristic (SROC) curve based on all IncRNAs. Abbreviations: SECS, sensitivity; SPEC, specificity; AUC, area under the curve. 
0.004, random-effects model). From this point of view, these analyses provide a promising way for determining whether HOTAIR functions as a biomarker for lymph node metastasis in $\mathrm{CC}$ patients.

For the prognostic values, most lncRNAs were identified by a single study, while only two (HOTAIR and PVT1) were reported by at least two studies. Our subsequent pooled data analyses discovered that high expression of HOTAIR is a strong predictor of short OS and DFS of CC patients. Consistent with the present meta-analysis, Miao et al. [36] pooled 63 studies with various solid carcinomas and found that a high level of HOTAIR predicted worse OS with a combined HR of 2.21 (95\%CI 1.77-2.74, $P<0.00001)$. In the subgroup analysis, higher levels of HOTAIR also indicated shorter OS in Asian populations $(\mathrm{HR}=2.06,95 \%$ CI $1.80-2.37, P<$ $0.00001)$. In general, high HOTAIR expression represents a significant risk factor for survival outcomes in the development of tumors. In addition, an increase in cellular expression of PVT1 was significantly associated with a decrease in overall survival. It follows that up-regulation of HOTAIR and PVT1 could be considered prognostic markers for $\mathrm{CC}$.
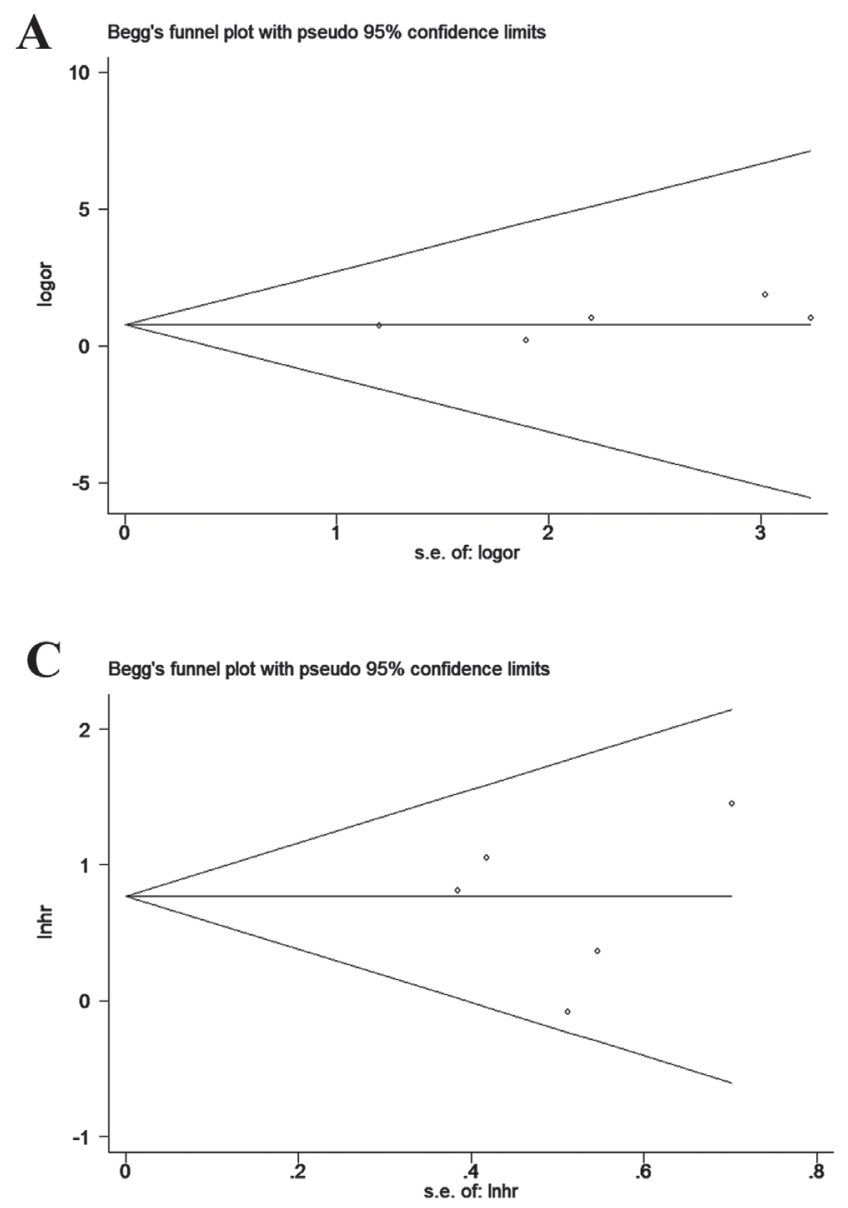

Regarding the diagnostic values, it was unlikely that an accurate assessment of the diagnostic performance of lncRNAs could be obtained due to the small sample sizes in the included studies. Therefore, the aim of our study was to summarize the results of individual studies and investigate the diagnostic value of lncRNAs for CC detection. After analyzing and pooling all of the included data, we found that the overall sensitivity and specificity of lncRNAs were 0.85 and 0.81 with an AUC value of 0.88 . Nevertheless, we were unable to perform advanced analysis because of the limited and insufficient research regarding other lncRNAs.

For one of the most extensively studied lncRNAs, HOTAIR, a high expression level is observed in many malignancies [37-39]. Consistent with our results, a number of studies have demonstrated that HOTAIR expression is related to clinical parameters and the prognosis of cancer patients. The biological role of HOTAIR in tumor cells may mediate the poor CC outcome. HOTAIR was introduced by Rinn et al. [40] as a spliced and polyadenylated RNA with 2,158 nucleotides and 6 exons. It functions as a molecular scaffold and interacts with polycomb repressive complex 2 (PRC2)
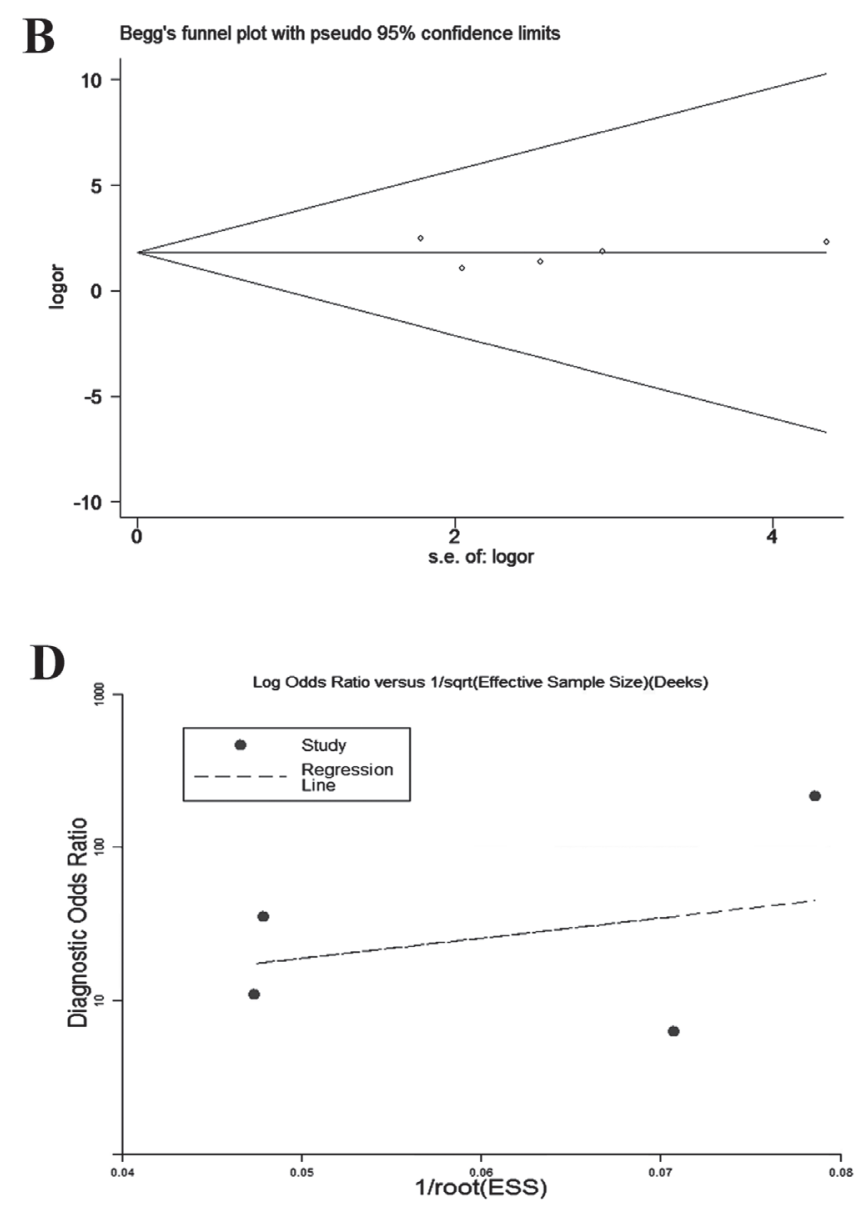

Figure 7: Begg's and Deeks' funnel plot for studies involved in the meta-analysis of HOTAIR expression and the clinical values of patients with CC. A. Tumor size B. Lymph node metastasis C. Prognosis D. Diagnosis. 
and lysinespecific demethylase1 (LSD1) complex to regulate gene expression. Approximately 854 genes with HOTAIR-induced PRC2 occupancy are implicated in inhibiting breast cancer progression, including classic favorable prognostic factors [41]. In addition, Padua et al. [42] have discovered a close connection between HOTAIR and epithelial-mesenchymal transition (EMT) and its role in inducing and maintaining cancer stem cells (CSCs). Furthermore, HOTAIR can function as a competitive endogenous RNA (ceRNA) in cancer cells, recruiting microRNAs to target various genes [43, 44].

Still, there are several limitations in identifying a correlation between aberrant expression of lncRNA and clinical values in the present meta-analysis. First, the arbitrary cut-off value for low or high levels of lncRNA in the patient samples differed between studies. Though qRT-PCR was used in all of the studies to quantify lncRNAs, the results may still be heterogeneous due to the utilization of different qRT-PCR primer sets across studies of the same lncRNA. Second, obstacles in achieving a sufficient follow-up period and homogenous endpoints limited the accuracy of the results. Third, the method of HR extrapolation from the Kaplan-Meier graph may also generate heterogeneity despite analysis by two independent reviewers to minimize this variation. Five of the records included in the systematic review did not report the HR directly. Therefore, the extrapolated HRs might be less reliable compared with reported statistics. Fourth, in this systematic review, most of the studies addressed different lncRNAs. Only 4 lncRNAs (HOTAIR, MALAT1, PVT1 and MEG3) were identified by at least two studies. Furthermore, the majority of patients are Asian, only one study with American patients. Therefore, most of the meta-analyses in our study contain insufficient records. Finally, a distinct heterogeneity was observed in the analysis of diagnostic value. Due to the small number and small sample sizes of the included studies, we did not conduct a meta-regression or meta-subgroup analyses.

To sum up, the strong clinical value of IncRNA expression in CC was confirmed in the present results, especially HOTAIR, a promising potential biomarker for lymph node metastasis and survival rate in cancer patients. Furthermore, IncRNA also exhibited appropriate accuracy for $\mathrm{CC}$ diagnosis. Further, more comprehensive and largescale studies are required to achieve a more persuasive conclusion.

\section{MATERIALS AND METHODS}

\section{Literature search strategies}

The aim of our systematic review and meta-analysis was to identify all the primary research articles that assessed the utility of candidate lncRNAs as biomarkers for clinical values in CC. A comprehensive search was performed in PubMed (Supplementary Table 3), Embase and Web of Science databases prior to February 10, 2017.

\section{Inclusion and exclusion criteria}

All of the included studies had to meet the following inclusion criteria: (1) the association between lncRNAs and cervical cancer was discussed with regard to clinicopathological features, prognostic or diagnostic values; (2) all the cancer patients were diagnosed based on a histopathological or cytological examination, considered the gold standard for diagnosis, and lncRNA expression in tumors or blood samples was estimated in the study; (3) studies provided sufficient data for extraction or calculation of the individual OR, HR and 95\%CI. Studies were excluded based on the following criteria: (1) duplicate publications; (2) reviews, letters, laboratory studies and meeting abstracts; (3) fewer than 30 sample cases; (4) studies without complete data.

\section{Data extraction and quality assessment}

Eligible publications were reviewed independently by two investigators. The following data were extracted: basic information of included records, characteristics of the patients, and essential data for systematic review and meta-analysis. When the $\mathrm{HR}$ and $95 \% \mathrm{CI}$ for survival analysis were unavailable, we calculated the HRs and their 95\%CIs using Kaplan-Meier curves and observed data provided by the authors based on the methods illustrated by Tierney et al. [45]. The methodological quality of prognostic studies was evaluated using the NewcastleOttawa-Scale (NOS) tool [46]. The NOS score has a maximum of nine and those studies $\geq 7$ were considered to be of high quality. Moreover, QUADAS-2 [47] was adopted to assess the quality of all the included diagnostic studies. The QUADAS-2 tool comprises four key domains: patient selection, index test, reference standard, flow and timing, and judge bias and applicability. This is an evidence-based tool for quality assessment intended for use with diagnostic accuracy studies, with a maximum score of seven.

\section{Statistical analysis}

Meta-analyses were performed using Stata version 12.0 (StataCorp, College Station, TX, USA). A different effect size (ES) was selected for each meta-analysis. (1) Pooled HRs and ORs with $95 \%$ CIs were used to evaluate the association between lncRNA expression and $\mathrm{CC}$ prognosis and clinicopathological features. The HRs and $95 \% \mathrm{CIs}$ were directly extracted from original articles or estimated from the existing data using methods 
previously reported by Tierney et al. [45]. An observed HR $>1$ implied a worse survival for patients with upregulated lncRNA expression. Conversely, an $\mathrm{HR}<1$ implied a worse survival for patients with decreased IncRNA expression [48]. The point estimate of the HR or OR was considered statistically significant at a level of $P<0.05$ if the $95 \%$ CI did not cover the value " 1 ". (2) Sensitivity, specificity, PLR, NLR, DOR, SROC curve, and AUC were used for the diagnostic meta-analysis. A heterogeneity test was conducted using Cochran's Q test and Higgins I-squared statistic. $I^{2}$ values $>50 \%$ indicated heterogeneity among studies [49]. When heterogeneity was observed $\left(I^{2}>50 \%\right)$, a random-effect model was used; otherwise, a fixed-effect model was used. Furthermore, publication bias was assessed by visual inspection and statistically evaluated by Begg's and Deeks' funnel plot, using Egger's test. Asymmetric funnel plots or $P<0.05$ in Egger's test suggest the existence of publication bias in the incorporated studies.

\section{CONFLICTS OF INTEREST}

The authors declare that they have no conflicts of interest.

\section{REFERENCES}

1. Torre LA, Bray F, Siegel RL, Ferlay J, Lortet-Tieulent J, Jemal A. Global cancer statistics, 2012. CA Cancer J Clin. 2015; 65:87-108.

2. Lynge E, Rygaard C, Baillet MV, Dugue PA, Sander BB, Bonde J, Rebolj M. Cervical cancer screening at crossroads. APMIS. 2014; 122: 667-73. https://doi.org/10.1111/ apm. 12279.

3. Siegel R, Naishadham D, Jemal A. Cancer statistics, 2013. CA Cancer J Clin. 2013; 63:11-30.

4. Salvatici M, Achilarre MT, Sandri MT, Boveri S, Vanna Z, Landoni F. Squamous cell carcinoma antigen (SCC$\mathrm{Ag}$ ) during follow-up of cervical cancer patients: role in the early diagnosis of recurrence. Gynecol Oncol. 2016; 142:115-19.

5. Maruyama R, Suzuki H. Long noncoding RNA involvement in cancer. BMB Rep. 2012; 45:604-11.

6. Mercer TR, Dinger ME, Mattick JS. Long non-coding RNAs: insights into functions. Nat Rev Genet. 2009; 10:155-59.

7. Yang G, Lu X, Yuan L. LncRNA: a link between RNA and cancer. Biochim Biophys Acta. 2014; 1839: 1097-109. https://doi.org/10.1016/j.bbagrm.2014.08.012.

8. Huang L, Damle SS, Booten S, Singh P, Sabripour M, Hsu J, Jo M, Katz M, Watt A, Hart CE, Freier SM, Monia BP, Guo S. Partial Hepatectomy Induced Long Noncoding RNA Inhibits Hepatocyte Proliferation during Liver Regeneration. PLoS One. 2015; 10:e132798.

9. Wu Y, Lyu H, Liu H, Shi X, Song Y, Liu B. Downregulation of the long noncoding RNA GAS5-AS1 contributes to tumor metastasis in non-small cell lung cancer. Sci Rep. 2016; 6:31093.

10. Zhang A, Zhao JC, Kim J, Fong KW, Yang YA, Chakravarti D, Mo YY, Yu J. LncRNA HOTAIR Enhances the Androgen-Receptor-Mediated Transcriptional Program and Drives Castration-Resistant Prostate Cancer. Cell Reports. 2015; 13:209-21.

11. Yang JP, Yang XJ, Xiao L, Wang Y. Long noncoding RNA PVT1 as a novel serum biomarker for detection of cervical cancer. Eur Rev Med Pharmacol Sci. 2016; 20:3980-86.

12. Liao LM, Sun XY, Liu AW, Wu JB, Cheng XL, Lin JX, Zheng M, Huang L. Low expression of long noncoding XLOC_010588 indicates a poor prognosis and promotes proliferation through upregulation of c-Myc in cervical cancer. Gynecol Oncol. 2014; 133:616-23.

13. Huang L, Liao LM, Liu AW, Wu JB, Cheng XL, Lin JX, Zheng M. Overexpression of long noncoding RNA HOTAIR predicts a poor prognosis in patients with cervical cancer. Arch Gynecol Obstet. 2014; 290:717-23.

14 Kim HJ, Lee DW, Yim GW, Nam EJ, Kim S, Kim SW, Kim YT. Long non-coding RNA HOTAIR is associated with human cervical cancer progression. Int J Oncol. 2015; 46:521-30.

15. Lee M, Kim HJ, Kim SW, Park SA, Chun KH, Cho NH, Song YS, Kim YT. The long non-coding RNA HOTAIR increases tumour growth and invasion in cervical cancer by targeting the Notch pathway. Oncotarget. 2016; 7:4455871. https://doi.org/10.18632/oncotarget.10065.

16. Zhang YM, Chen XZ. Expression of long non-coding RNA HOTAIR in cervical cancer and its effect on proliferation and apoptosis of HeLa cells. TUMOR. 2015; 35:446-52. https://doi.org/10.3781/j.issn.1000-7431.2015.33.791

17. Sun J, Chu H, Ji J, Huo G, Song Q, Zhang X. Long noncoding RNA HOTAIR modulates HLA-G expression by absorbing miR-148a in human cervical cancer. Int J Oncol. 2016; 49:943-52.

18. Chen X, Liu L, Zhu W. Up-regulation of long non-coding RNA CCAT2 correlates with tumor metastasis and poor prognosis in cervical squamous cell cancer patients. Int $\mathrm{J}$ Clin Exp Pathol. 2015; 8:13261-66.

19. Yang M, Zhai X, Xia B, Wang Y, Lou G. Long noncoding RNA CCHE1 promotes cervical cancer cell proliferation via upregulating PCNA. Tumour Biol. 2015; 36: 7615-22. https://doi.org/10.1007/s13277-015-3465-4.

20. Yang L, Bai HS, Deng Y, Fan L. High MALAT1 expression predicts a poor prognosis of cervical cancer and promotes cancer cell growth and invasion. Eur Rev Med Pharmacol Sci. 2015; 19:3187-93.

21. Zhang Y, Wang T, Huang HQ, Li W, Cheng XL, Yang J. Human MALAT-1 long non-coding RNA is overexpressed in cervical cancer metastasis and promotes cell proliferation, invasion and migration. J BUON. 2015; 20: 1497-503.

22. Cao Y, Liu Y, Lu X, Wang Y, Qiao H, Liu M. Upregulation 
of long noncoding RNA SPRY4-IT1 correlates with tumor progression and poor prognosis in cervical cancer. FEBS Open Bio. 2016; 6:954-60.

23. Kim HJ, Eoh KJ, Kim LK, Nam EJ, Yoon SO, Kim $\mathrm{KH}$, Lee JK, Kim SW, Kim YT. The long noncoding RNA HOXA11 antisense induces tumor progression and stemness maintenance in cervical cancer. Oncotarget. 2016; 7:83001-83016. https://doi.org/10.18632/oncotarget.12863.

24. Wang YF, Zhang S, Li XQ, Wang Y. Expression of lncRNA HULC in cervical cancer and its correlation with tumor progression and patient survival. Eur Rev Med Pharmacol Sci. 2016; 20:3987-91.

25. Zhang S, Zhang G, Liu J. Long noncoding RNA PVT1 promotes cervical cancer progression through epigenetically silencing miR-200b. APMIS. 2016; 124:649-58. https://doi. org/10.1111/apm.12555.

26. Zhang D, Sun G, Zhang H, Tian J, Li Y. Long non-coding RNA ANRIL indicates a poor prognosis of cervical cancer and promotes carcinogenesis via PI3K/Akt pathways. Biomed Pharmacother. 2017; 85:511-516. https://doi. org/10.1016/j.biopha.2016.11.058.

27. Hu Y, Sun X, Mao C, Guo G, Ye S, Xu J, Zou R, Chen J, Wang L, Duan P, Xue X. Upregulation of long noncoding RNA TUG1 promotes cervical cancer cell proliferation and migration. Cancer Med. 2017; 6:471-82.

28. Cao S, Liu W, Li F, Zhao W, Qin C. Decreased expression of IncRNA GAS5 predicts a poor prognosis in cervical cancer. Int J Clin Exp Pathol. 2014; 7:6776-83.

29. Jiang S, Wang HL, Yang J. Low expression of long noncoding RNA LET inhibits carcinogenesis of cervical cancer. Int J Clin Exp Pathol. 2015; 8:806-11.

30. Zhang J, Yao T, Wang Y, Yu J, Liu Y, Lin Z. Long noncoding RNA MEG3 is downregulated in cervical cancer and affects cell proliferation and apoptosis by regulating miR-21. Cancer Biol Ther. 2016; 17:104-13.

31. Kobayashi R, Miyagawa R, Yamashita H, Morikawa T, Okuma K, Fukayama M, Ohtomo K, Nakagawa K. Increased expression of long non-coding RNA XIST predicts favorable prognosis of cervical squamous cell carcinoma subsequent to definitive chemoradiation therapy. Oncol Lett. 2016; 12:3066-74.

32. Zhang J, Lin Z, Gao Y, Yao T. Downregulation of long noncoding RNA MEG3 is associated with poor prognosis and promoter hypermethylation in cervical cancer. J Exp Clin Cancer Res. 2017; 36: 5. https://doi.org/10.1186/ s13046-016-0472-2.

33. Egger M, Davey Smith G, Schneider M, Minder C. Bias in meta-analysis detected by a simple, graphical test. BMJ. 1997; 315:629-34.

34. Deeks JJ, Macaskill P, Irwig L. The performance of tests of publication bias and other sample size effects in systematic reviews of diagnostic test accuracy was assessed. J Clin Epidemiol. 2005; 58:882-93.

35. Cai B, Wu Z, Liao K, Zhang S. Long noncoding RNA
HOTAIR can serve as a common molecular marker for lymph node metastasis: a meta-analysis. Tumour Biol. 2014; 35: 8445-50. https://doi.org/10.1007/s13277-0142311-4.

36. Miao Z, Ding J, Chen B, Yang Y, Chen Y. HOTAIR overexpression correlated with worse survival in patients with solid tumors. Minerva Med. 2016; 107:392-400.

37. Dong L, Hui L. HOTAIR Promotes Proliferation, Migration, and Invasion of Ovarian Cancer SKOV3 Cells Through Regulating PIK3R3. Med Sci Monit. 2016; 22:325-31.

38. Fang S, Gao H, Tong Y, Yang J, Tang R, Niu Y, Li M, Guo L. Long noncoding RNA-HOTAIR affects chemoresistance by regulating HOXA1 methylation in small cell lung cancer cells. Lab Invest. 2016; 96:60-68.

39. Luo ZF, Zhao D, Li XQ, Cui YX, Ma N, Lu CX, Liu MY, Zhou Y. Clinical significance of HOTAIR expression in colon cancer. World J Gastroenterol. 2016; 22:5254-59.

40. Rinn JL, Kertesz M, Wang JK, Squazzo SL, Xu X, Brugmann SA, Goodnough LH, Helms JA, Farnham PJ, Segal E, Chang HY. Functional demarcation of active and silent chromatin domains in human HOX loci by noncoding RNAs. Cell. 2007; 129:1311-23.

41. Gupta RA, Shah N, Wang KC, Kim J, Horlings HM, Wong DJ, Tsai MC, Hung T, Argani P, Rinn JL, Wang Y, Brzoska P, Kong B, et al. Long non-coding RNA HOTAIR reprograms chromatin state to promote cancer metastasis. Nature. 2010; 464:1071-76.

42. Pádua Alves C, Fonseca AS, Muys BR, de Barros E Lima Bueno R, Bürger MC, de Souza JE, Valente V, Zago MA, Silva WA Jr. Brief report: the lincRNA Hotair is required for epithelial-to-mesenchymal transition and stemness maintenance of cancer cell lines. Stem Cells. 2013; 31:2827-32.

43. Ma MZ, Li CX, Zhang Y, Weng MZ, Zhang MD, Qin YY, Gong W, Quan ZW. Long non-coding RNA HOTAIR, a c-Myc activated driver of malignancy, negatively regulates miRNA-130a in gallbladder cancer. Mol Cancer. 2014; $13: 156$.

44. Liu XH, Sun M, Nie FQ, Ge YB, Zhang EB, Yin DD, Kong R, Xia R, Lu KH, Li JH, De W, Wang KM, Wang ZX. Lnc RNA HOTAIR functions as a competing endogenous RNA to regulate HER2 expression by sponging miR-331-3p in gastric cancer. Mol Cancer. 2014; 13:92.

45. Tierney JF, Stewart LA, Ghersi D, Burdett S, Sydes MR. Practical methods for incorporating summary time-to-event data into meta-analysis. Trials. 2007; 8:16.

46. Stang A. Critical evaluation of the Newcastle-Ottawa scale for the assessment of the quality of nonrandomized studies in meta-analyses. Eur J Epidemiol. 2010; 25:603-05.

47. Whiting PF, Rutjes AW, Westwood ME, Mallett S, Deeks JJ, Reitsma JB, Leeflang MM, Sterne JA, Bossuyt PM, and QUADAS-2 Group. QUADAS-2: a revised tool for the quality assessment of diagnostic accuracy studies. Ann Intern Med. 2011; 155:529-36. 
48. Ding X, Wan X, Jiang H, Song H, Fang Y, Chen S, Li P, Guo J. The clinical value of ncRNAs in gastric cancer: a systematic review and meta-analyses. Tumour Biol. 2015; 36: 4017-25. https://doi.org/10.1007/s13277-015-3411-5.
49. DerSimonian R, Laird N. Meta-analysis in clinical trials. Control Clin Trials. 1986; 7:177-88. 